\title{
LEITURA LITERÁRIA E META-APRENDIZADO: REFLEXÕES E SUBSÍDIOS PARA O ENSINO DE LITERATURA NO ENSINO FUNDAMENTAL I
}

Rodrigo Corrêa Martins Machado (UFF)

Resumo: Este trabalho faz parte de uma pesquisa de pós-doutorado cujo objetivo foi investigar o ensino de Literatura na Educação Básica. No caso presente, a partir da constatação de que poucas são as investigações que se debruçam sobre ensino literário no Ensino Fundamental I, busco refletir acerca da importância da formação de leitores desde a infância, bem como da formação de profissionais capacitados para este empreendimento. Desta maneira, analisou-se um questionário aplicado a alunos do quarto período de pedagogia com intuito de investigar o conhecimento prévio dos licenciandos quanto à importância do ensino de literatura. Metodologicamente, este trabalho tem como base principal o conceito de Meta-aprendizado desenvolvido por Norman Jackson (2004). A partir de tal conceito, é possível refletir e propor um ensino de literatura em que os conhecimentos e desejos dos alunos serão respeitados, contribuindo para que tornem-se sujeitos ativos na construção de seu próprio conhecimento, reconhecendo-os enquanto pessoas distintas que possuem maneiras diferentes de aprender. Ao analisar as respostas ao questionário, foi possível constatar que muitos dos licenciandos possuíam uma visão atrelada à ideia de que a literatura deve ser utilizada como pretexto para o ensino de outros campos do saber, desenvolvimento de habilidades de leitura e escrita, trabalho com gramática, ou gêneros textuais. Entretanto, também encontramos respostas em que a visão de ensino de literatura estaria diretamente vinculada à formação de leitores autônomos, capazes de escolher os seus próprios clássicos e de gerirem a sua própria construção de conhecimento e sentidos.

Palavras-chave: Ensino de Literatura; Ensino Fundamental I; Metaaprendizado.

Abstract: This work is part of a postdoctoral research whose objective was to investigate the teaching of Literature in Brazilian Basic Education. In the present case, based on the fact that few investigations are carried 
out on literary education in Elementary School I, we seek to reflect on the importance of the training of readers from childhood, as well as the training of professionals qualified for this project. In this way, a questionnaire was applied to students of the fourth period of Pedagogy in order to investigate the prior knowledge of the future teachers regarding the importance of teaching literature. Methodologically, this work has as main base the concept of Meta-learning developed by Norman Jackson (2004). From this concept, it is possible to reflect and propose literature teaching in which students' knowledge and desires will be respected, contributing to their becoming active subjects in the construction of their own knowledge, recognizing them as distinct people who have ways different from learning. When analyzing the answers to the questionnaire, it was possible to verify that many of the future teachers had a vision linked to the idea that literature should be used as a pretext for teaching other fields of knowledge, developing reading and writing skills, working with grammar, or textual genres. However, we also find answers in which the view of literature teaching would be directly linked to the formation of autonomous readers, capable of choosing their own classics and managing their own construction of knowledge and meanings.

Keywords: Teaching Literature; Elementary School I; Meta-learning.

O mosquito escreve

O mosquito pernilongo trança as pernas, faz um $M$, depois, treme, treme, treme, faz um $O$ bastante oblongo, faz um $S$. O mosquito sobe e desce. Com artes que ninguém vê, faz um $Q$, faz um $U$, e faz um $I$.

Este mosquito esquisito cruza as patas, faz um T. E aí, 
se arredonda e faz outro $O$, mais bonito.

$\mathrm{Oh!}$

Já não é analfabeto, esse inseto,

pois sabe escrever seu nome.

Mas depois vai procurar alguém que possa picar, pois escrever cansa, não é, criança?

E ele está com muita fome. (MEIRELES, 1977, p.40)

\section{ENSINO DE LITERATURA NA EDUCAÇÃO BÁSICA}

É no Ensino Fundamental I que a criança será introduzida a cada um dos campos do conhecimento formal, trabalhados na e pela escola, e aprenderá os princípios básicos. E isso diz respeito também à literatura, uma vez que, ao adentrar na escola, as crianças terão ainda mais contato com esse campo do saber e serão iniciadas (ou darão continuação) no processo de formação enquanto leitores. Isto, por si só, já denota uma importância ímpar no que tange às reflexões sobre o ensino de literatura nesta etapa do ensino. E, após tal constatação, a pergunta a ser feita é: como é pensado o ensino literário no Ensino Fundamental I?

Para, de alguma maneira, responder a tal questionamento destaco que ao buscar pesquisas relacionadas ao ensino de 
literatura nessa etapa do conhecimento, noto uma grande falta de trabalhos acadêmicos. A maior parte das pesquisas desenvolvidas acerca do ensino de literatura são pensadas para o Ensino Fundamental II e para o Ensino Médio (áreas de atuação dos profissionais formados em Licenciaturas em Letras). Quando voltadas para o período que compreende do 10 ao 5ㅇaㅇ anos do Ensino Fundamental, os trabalhos científicos enfatizam muito mais o objeto em si (ou seja, a obra literária infanto-juvenil) do que o ensino. Concomitantemente, ou mesmo consequentemente, é grande a deficiência na formação dos pedagogos no que diz respeito à formação de leitores de literatura. Isso é um dado alarmante, já que difícil será contribuir para que tenhamos sujeitos que leem literatura, como também para melhorar a Educação Básica se seus profissionais não tiverem uma formação adequada e satisfatória.

A Universidade tem um importante papel no que diz respeito às falhas apontadas, pois, enquanto instância de poder que pesquisa e constrói as balizas para a educação básica, além de formar os profissionais capacitados para atuar efetivamente no espaço escolar, necessita modificar o seu modo de compreender o ensino - no nosso caso, de literatura e leitura literária-, descentrando-o e pluralizando-o. Isso, necessariamente, possibilita que o ensino básico em 
algum momento acompanhe esse movimento, não mais educando cidadãos que apenas sabem dizer acerca das técnicas linguísticas e estilísticas que há na construção de uma obra literária, e sim forme leitores de literatura e de mundo capazes de assumir o papel ativo na construção do saber, na leitura e na eleição de seu próprio cânone, de forma que cada livro fale diretamente com cada leitor e que, dessa relação, nasça uma construção de conhecimento crítico capaz de permitir àquele que lê incluir ou não o texto lido entre os seus interesses.

Outro dado que pode ser relevante neste início do trabalho é que, como Professor do Ensino Superior do Curso de Pedagogia, ministrando aulas em disciplinas relacionadas à Didática da Língua Portuguesa e Literaturas (para alunos do 1ㅇ e 4으 período de Pedagogia), me deparei com situações também inesperadas, que poderão contribuir para o aprofundamento daquilo que pontuarei aqui. Primeiramente, devo notar que, ao contrário de outras Universidades, não existe na instituição em que leciono uma disciplina de literatura infantil ou infantojuvenil na formação desses profissionais. Isso me preocupa, pois se sabe que a ação pedagógica no Ensino Fundamental I, com destaque para o período de alfabetização dos alunos, privilegia o trabalho com narrativas e livros infantis. As obras literárias 
pertencentes ao gênero "literatura infantil", como o próprio nome indica, são textos destinados às crianças, os quais propiciam

"[...] uma reorganização das percepções do mundo e, desse modo, possibilitam uma nova ordenação das experiências existenciais da criança. A convivência com textos literários provoca a formação de novos padrões e o desenvolvimento do senso crítico". (CADEMARTORI, 1986, p.19)

Devido ao fato de grande parte das crianças já conhecerem histórias clássicas (ou não) e livros infantis antes mesmo de adentrarem no ambiente escolar, trabalhar a leitura e a escrita a partir desse conhecimento que elas já trazem de casa torna o ensino-aprendizagem algo muito mais prazeroso e significativo. Como é possível observar no poema "O mosquito escreve", de Cecília Meireles, que utilizei como epígrafe deste capítulo, a obra literária escrita para crianças tem como objetivo dialogar e adentrar com o universo infantil: é muito mais lúdica, brinca com sons e palavras, de maneira a não só chamar a atenção do leitor, mas também a instigar alunos em processo de letramento e alfabetização no conhecimento dos sons e letras.

Muitos dos meus alunos de graduação me disseram que não se consideravam leitores, e poucos tinham conhecimentos 
acerca do que seria a literatura infantil e como trabalhar com textos literários na escola. Notei que era preciso implementar, nas minhas aulas, atividades que propiciassem aos futuros professores um começo de formação enquanto leitores. Isso é bastante preocupante se pensarmos que, para ensinar tanto a ler (textos de literatura ou não) quanto a escrever, torna-se imprescindível que os profissionais responsáveis sejam bons leitores e escrevam bem, assim como é preciso pensar: como profissionais escolherão obras literárias a serem trabalhadas (e se dedicarão à formação de leitores), se eles mesmos desconhecem esse campo do saber?

Diante desse quadro, para o desenvolvimento deste trabalho, buscarei empreender uma discussão acerca da importância do ensino de literatura, por quê e para quê trabalhar esse campo do saber no Ensino Fundamental I. Para tanto, metodologicamente, basearei minhas reflexões e a análise de um questionário ministrado aos meus alunos do quarto período de pedagogia no conceito de metaaprendizado desenvolvido por Norman Jackson (2004).

\section{O PAPEL DA ESCOLA NA FORMAÇÃO DO LEITOR}

Muito se fala sobre os problemas do ensino de literatura na educação básica (e pública, sobretudo) brasileira, apontandose, como um dos grandes vilões desse processo, o livro 
didático. Realmente, longe de contestar isso, pontuo aqui algumas razões dessa vilania: a falta de contato dos alunos com a obra literária (como formar leitores, se os alunos não são familiarizados com o livro?); a utilização fragmentária de textos de literatura com fins de ensino gramático ou moral; a substituição da leitura das obras literárias pelo ensino da história da literatura e suas correntes. Além disso, a noção de leitura proposta pelos livros didáticos, de acordo com Gerhardt et al (2015), não corresponde a como o ser humano cogniza quando lê, e que as atividades escolares, ao não "promoverem a leitura como ação cognitiva plena, não permitem aos professores e alunos compreender as capacidades destes últimos como leitores, nem identificar eventuais dificuldades de leitura para saná-las em atividades posteriores" (p.182).

Em grande parte das atividades referentes à literatura encontradas nos livros didáticos, é possível observar atividades de cópia-colagem, em que as respostas para as questões referentes à interpretação e discussão dos conteúdos encontram-se explícitas no próprio texto que as precedem; o texto é tomado como fonte única de informação, o que facilita aos docentes trabalhar com a quantificação e obtenção de resultados; as atividades de leitura literária não apresentam objetivos claros de leitura; e os saberes dos 
alunos são desconsiderados, uma vez que a eles é proposto ensinar apenas o que supostamente eles não sabem.

Vejo como um dos maiores problemas da escola, e de forma ainda mais específica dos professores ao trabalharem com obras de literatura, a tentativa de didatizar os textos, isto é, produzir e esperar respostas objetivas e fechadas por parte dos alunos. Não é incomum encontrar pessoas "traumatizadas" com as aulas de literatura porque a resposta que deram a alguma questão elaborada pelo professor foi tida como incorreta. As leituras feitas a partir de um texto literário por, dentre outros motivos, se relacionarem a pessoas com vivências, culturas e idades diferentes são distintas. Atento ao que diz Ivete Walty (2011, p.52), concordo com ela quando diz que

[...] se o que caracteriza o texto dado como literário é justamente sua polissemia, suas lacunas a serem preenchidas pelo leitor, mesmo quando se tenta guiar esse leitor em seu ato de leitura, sentidos se formam que escapam ao controle do mediador da leitura. A literatura é uma das produções sociais onde o imaginário tem espaço de circulação garantido. E é lá que, ao lado das regras, encontra-se a possibilidade de transgressão [...].

É preciso, ao pensar o ensino de literatura, questionar as burocracias didáticas acopladas a regras estritas, rígidas 
e castradoras. Além disso, também é necessário formar profissionais que fujam do uso fragmentado, deslocado, manipulado e pré-estabelecido do texto literário, para serem educadores que entendam que, pelo fato de o texto literário ser polissêmico, mais de um sentido é possível em sua leitura e que o próprio texto em si delimitará se a interpretação é insólita ou não.

A independência e autoconhecimento nas iniciativas de prática com a linguagem me remetem ao conceito de metaaprendizado desenvolvido por Norman Jackson. Tal conceito foi utilizado pela primeira vez por John Biggs em 1985 para descrever o estado de uma pessoa de estar ciente e tomar o controle acerca de seu próprio aprendizado. A questão de se saber sobre o que é o meta-aprendizado leva a outra: "o que é o aprendizado?". Para Jackson (2004, p.392-393), tratase de uma mistura de experiências, valores, informações contextualizadas que fornecem uma estrutura para avaliar e incorporar novas experiências e informações e para imaginar coisas novas. A ideia de meta-aprendizado, por sua vez, relaciona-se à necessidade (ou ao desejo) de as pessoas controlarem o seu próprio aprendizado, criando planos e estratégias para atingirem os objetivos desejados. Logo:

This conception of learning means that although we may encounter the same 
experience or may be confronted by the same new knowledge, the sense we make of it, the value we place on it and our capacity to make use of it, will be unique to each of us. Using this reasoning, metalearning - high-level thinking about learning and how we acquire new learning, must also be unique to each of us. (JACKSON, 2004, p.393).

O conceito de meta-aprendizado converge diretamente com a habilidade necessária para a leitura do texto literário, uma vez que, a partir dele é possível refletir e propor um ensino de literatura em que se respeitem e considerem os conhecimentos/desejos dos alunos, e se contribua para que eles se tornem sujeitos ativos na construção de seu próprio conhecimento, reconhecendo-os enquanto pessoas distintas que possuem maneiras diferentes de aprender. Ademais, ao se reconhecerem enquanto participantes do processo de significação, único em relação à leitura literária, os alunos cada vez mais verão significado nas atividades desenvolvidas. Dessa maneira, os discentes paulatinamente se tornarão mais conscientes acerca da maneira como aprendem, dos processos (ações e comportamentos) necessários para que controlem o seu próprio aprendizado, eles terão mais autonomia para aprender e possivelmente maior sucesso no processo de ensino-aprendizagem/leitura de textos literários. 
O conceito de meta-aprendizado me permite postular que, ao contrário do que vem sendo feito em muitas escolas e ainda em pesquisas acadêmicas que enfatizam os conteúdos a serem ensinados, é preciso escutar e reconhecer aqueles para quem se ensina algo. No caso da literatura, é imprescindível encorajar as crianças, adolescentes e até mesmo adultos à leitura por todos os meios, inclusive a dos livros que os críticos profissionais consideram com condescendência ou como desprezo, como Harry Potter e outros best sellers, uma vez que obras como essa levam milhares de adolescentes ao hábito de leitura e Ihes possibilita uma primeira leitura de mundo, a partir da qual os professores podem se aprofundar em novas leituras e questões mais complexas, contribuindo para uma aproximação entre leitor e literatura. Ou seja, a escola tem o papel primordial de formar leitores de literatura, respeitando os seus interesses e gostos, sem impor aos alunos um ensino mecânico, burocrático, que privilegie apenas os livros clássicos (e os utilize como pretexto para ensinar conteúdos gramaticais), os quais, pela própria questão da linguagem e do afastamento temporal, podem não cativar os leitores.

O que proponho, enquanto educador e professor que forma profissionais da Educação Básica, é que invistamos na formação 
de leitores que, instigados pelos textos, produzam sentidos conforme os diálogos que estabelecerão com as histórias que lerem, "um leitor que, paradoxalmente, é capaz de se safar até mesmo das camisas de força impostas pela escola e sociedade, na medida em que produz sentidos que fogem ao controle inerente à leitura e sua metodologia" (WALTY, 2011, p.52). Ou seja, leitores que, reconhecendo-se enquanto agentes no processo de significação da leitura literária, aprenderão a agenciar os procedimentos necessários para o seu próprio aprendizado, pessoas autônomas que encontrarão significados e objetivos nos textos que lerem.

Em relação ao meta-aprendizado, o aluno leitor que produz significados reconhece os processos de elaboração literária em que se vê inserido e, assim, terá instrumentos para efetuar uma opção, de tornar-se efetivamente leitor de literaturas, como distingue Calvino "[...] as escolhas que contam são aquelas que ocorrem fora e depois da escola" (CALVINO, 2007, p.13). "É só nas leituras desinteressadas que pode acontecer deparar-se com aquele que é o 'seu' livro" (idem). É bastante relevante ter em mente que, atualmente, com a modernização do ensino e o surgimento de novas práticas pedagógicas e tecnologias, a criança assume o papel ativo na construção do saber, na leitura e na construção de seu próprio cânone, de forma que cada 
livro fale diretamente com cada leitor e que, dessa relação, nasça uma construção de conhecimento crítico, mediada pela escola (professores, bibliotecários), capaz de permitir àquele que lê incluir ou não o texto lido entre os seus interesses. 0 professor, por mais que se depare com situações limitantes, como acontece em algumas escolas onde há falta de materiais, por exemplo, consciente do papel ativo do aluno na leitura, pode e deve estimulá-lo com atividades nas quais o livro não é visto como mero objeto estético e sim como possibilidade de mudança, transformação. Para isso, é preciso oferecer ao aluno leituras que lhe interessem, que se relacionem com o seu universo sociocultural, desenvolver projetos de leitura em que cada aluno se sinta inserido, desenvolver atividades a serem compartilhadas com os demais colegas.

Como se sabe, a leitura escolar perpassa os textos selecionados pela Instituição e pelo Estado, os quais têm sim uma intenção ideológica, política, social e cultural, e isso, durante muito tempo, corroborou com a hierarquização da própria literatura e no ensino. Dessa forma, textos que faziam uso semelhante da linguagem, que contavam histórias parecidas, eram "classificados" de maneira distinta. Por exemplo, houve tempo em que produções literárias feitas por mulheres, com temática homossexual, relacionadas às minorias 
de uma maneira ampla, não foram consideradas literatura, ou, quando eram, classificavam-nas como "menores". Para Márcia Abreu (2006), o que faz uma obra ser declarada "literária" são as instâncias de poder, como a Universidade, as revistas especializadas, os livros didáticos, os suplementos culturais dos grandes jornais. As instâncias de poder, as quais introduziram a literatura como disciplina escolar, difundiram a ideia de que ela é um bem comum ao ser humano, que deve ser lida por todos e da mesma maneira (ABREU, 2006, p.58). E, é importante ressaltar, durante muito tempo essas instâncias estavam diretamente relacionadas a um desejo de "elitização" social, de forma que temas articulados a minorias étnicas, sociais e sexuais remetiam à obra literária que abordava tais temas como "menor".

Ainda ao se falar a respeito do ensino escolar de literatura, trago aqui talvez o ponto mais instigante desse trabalho, que é o escutar os futuros profissionais da educação sobre o que pensam acerca desse tópico. Para tanto, pedi aos meus alunos do quarto período de Pedagogia que respondessem, no primeiro dia de aula, a um pequeno questionário no qual havia duas questões: 1) O que é, para você, ensinar literatura? 2) Para você, qual a importância do ensino de literatura?..

Destaco que a atividade do questionário foi feita antes do início das aulas em que discutiríamos o ensino de literatura, 
pois meu intuito é, através das respostas obtidas, investigar o conhecimento prévio deles acerca da importância da literatura e do ensino da mesma nas escolas. O total de alunos que respondeu a essa atividade foi de 10 pessoas. Abaixo, transcrevo as respostas recebidas:

\section{Aluno 1}

\section{Questão}

Resposta

O que é, para você, Ensinar literatura é ensinar literatura? apresentar ao aluno todo um mundo a ser explorado, onde - aluno conseguirá adquirir conhecimento sobre a cultura, o passado, o presente e muitas vezes sobre si mesmo.

Para você, qual a É importante, pois transmite importância do ensino de ao aluno a vontade de formar literatura? opiniões próprias, de explorar outra época e ideia, o ajuda a ver o mundo de maneira mais autêntica, o ajuda a ter mais empatia e a se conectar melhor com as pessoas. 


\section{Aluno 2}

\section{Questão}

\section{Resposta}

O que é, para você, Ensinar literatura é abrir portas ensinar literatura? para o aluno conhecer o quanto é rico e variável nossa língua.

Para você, qual a É também de grande importância do ensino importância. Além de fazer o de literatura? aluno tomar gosto pela leitura literária e conhecer vários tipos de leitura (poesia, rima e versos).

\section{Aluno 3}

\section{Questão}

O que é, para você, ensinar literatura? contos, poemas, histórias.

Para você, qual a Terconhecimento de literatura. importância do ensino de literatura?

\section{Aluno 4}

\section{Questão}

O que é, para você, ensinar literatura?

\section{Resposta}

Ensinar literatura é abrir os olhos e a mente do aluno para um amplo vocabulário e várias culturas. 
Para você, qual a A importância da literatura importância do ensino é agregar novos "valores" à de literatura? linguagem e a outros saberes como os culturais.

\section{Aluno 5}

\section{Questão}

\section{Resposta}

O que é, para você, Para mim, ensinar literatura ensinar literatura? é ensinar os tipos de textos, ou seja, para cada ocasião existe uma maneira de se escrever e esse expressar.

Para você, qual a Ensinar literatura é importância do ensino de importante para que os literatura? alunos saibam como se leem determinados textos.
Aluno 6
Questão
Resposta
O que é, para você,
Ensinar literatura é ensinar a ensinar literatura? interpretar diversos textos. 
Para você, qual a Sua importância é que além importância do ensino de de ler qualquer texto é preciso literatura? saber interpretá-lo.

\section{Aluno 7}

\section{Questão}

\section{Resposta}

O que é, para você, Ensinar literatura na minha ensinar literatura?

opinião é mergulhar um pouco na história e enxergar mais poesia nas coisas a nossa volta.

Para você, qual a Acredito que a literatura importância do ensino de nos leva a ter uma visão mais literatura? sensível das coisas, nos leva a refletir sobre os momentos e épocas que foram marcantes na história.

\section{Aluno 8}

\section{Questão}

\section{Resposta}

O que é, para você, Ensinar literatura é ensinar ensinar literatura? a ler, inserir o indivíduo em um mundo de leitura. 
Para você, qual a É importante para o importância do ensino de indivíduo ser inserido no literatura? mundo da literatura, ser inserido no meio dessa cultura.

\section{Aluno 9}

\section{Questão}

\section{Resposta}

O que é, para você, A literatura para mim ensinar literatura? deveria ser oferecida sempre ao aluno por possibilitar o aluno a ter o conhecimento de diversas obras e despertar nesse aluno o prazer pela leitura.

Para você, qual a A literatura se torna importância do ensino de essencial, pois sem a leitura é literatura? impossível que o aluno venha a se sentir o prazer pela escrita. É despertar o lúdico através de obras diversas e trazer esse aluno a se descobrir como ser pensante e capaz de transferir seus pensamentos e sentimentos através da escrita. 


\section{Aluno 10}

\section{Questão}

\section{Resposta}

O que é, para você, ensinar literatura?

Para você, qual a Na literatura, o aluno é importância do ensino de levado a conhecer várias literatura? culturas, não só no seu país, na sua cidade, ou no seu estado, mas no mundo, porque é através da leitura que muitas pessoas conhecem outros modos de vida e assim adquirem conhecimentos valorosos.

Antes de iniciar a exploração das respostas dos alunos, quero destacar que o meu intuito não é julgar o que me foi entregue e sim observar qual o conhecimento prévio dos alunos quanto ao ensino de literatura e a importância de trabalhar esse campo do saber com seus futuros alunos, assim como me é impossível não analisar a visão de literatura que a eles foi passada durante toda a Educação Básica. Ao me deparar com essas respostas, a primeira coisa que me veio à mente foi pensar nas aulas de literatura que esses futuros professores tiveram (ou não). 
Como é possível observar nas respostas que obtive com o questionário, com destaque para os Alunos 1, 9 e 10, algumas são bastante interessantes por, de alguma forma, remeterem à ideia de leitor autônomo, crítico de si e da realidade que o circunda, e mesmo de alteridade no que diz respeito à escrita e leitura literária. Isso me permite afirmar que a visão de leitura literária, por trás de tais respostas, mostra sujeitos que entendem esse campo do saber muito além da mera estruturação de escolas e histórias da literatura, assim como não veem o texto literário enquanto um caminho de trabalhar questões gramaticais. Retorno, pois, ao Aluno 1 quando diz que "Ensinar literatura é apresentar ao aluno todo um mundo a ser explorado, onde o aluno conseguirá adquirir conhecimento sobre a cultura, o passado, o presente e muitas vezes sobre si mesmo". Isso é muito interessante, uma vez que, em conformidade com Jean-Paul Sartre em $O$ existencialismo é um humanismo (2013), os Outros são a condição da própria existência do Eu, assim como para o autoconhecimento. No tocante ao ensino de literatura, é válido considerar que as obras literárias, enquanto criação ficcional de personagens, mundos, histórias distintas da vivência do próprio leitor, possibilitamIhe contato com os Outros de si, o conhecimento do mundo e o autoconhecimento, e, por consequência, a construção 
de si como cidadão. A partir do momento em que o leitor se sente inserido no processo de leituras (através de obras que tratem de assuntos de seu interesse, por exemplo), ele poderá aprender a agenciar o seu próprio processo de aprendizado e buscar outros textos de forma a ampliar os seus horizontes.

As demais respostas dos alunos 2, 3, 4, 5, 6, 7 e 8 apresentam visões ainda problemáticas, a meu ver, em relação ao campo do saber literário e seu ensino. Algumas delas, por exemplo, focam-se sobretudo no estudo da literatura com fins outros que não o trabalho com os textos literários. Vejamos o Aluno 7, que diz "Ensinar literatura na minha opinião é mergulhar um pouco na história", ou, ainda, "Acredito que a literatura nos leva a ter uma visão mais sensível das coisas, nos leva a refletir sobre os momentos e épocas que foram marcantes na história". Como é possível perceber, para ele a literatura é um meio através do qual poderá aprender e refletir sobre a história da humanidade. No entanto, desde A Poética de Aristóteles, sabemos que os textos literários possuem verossimilhança, mas nenhuma obrigação com o real. Obviamente, há gêneros, como o "Romance Histórico" e a "Metafiç̧ão Historiográfica", que possuem um diálogo intenso com a história, mas sem nenhum intuito de verdade, 
mostrando outras possíveis visões acerca de fatos ocorridos ao longo do tempo. Ademais, quantas não são as narrativas insólitas? Os contos fantásticos?

As respostas dos Alunos 2, 5, 6 e 8 me chamam ainda mais atenção porque estão de acordo com o que me deparei nas escolas em que trabalhei quando professor do Ensino Básico: a visão de que a literatura é um meio para desenvolver habilidades linguísticas e gramaticais relacionadas aos conteúdos de Língua Portuguesa. O Aluno 2, por exemplo, afirma que "Ensinar literatura é abrir portas para o aluno conhecer o quanto é rica e variável nossa língua". Essa visão está estritamente vinculada à variação linguística. Obviamente, é possível perceber a variação da língua através das mudanças, povos e culturas em textos literários, porém essa resposta está vinculada à pergunta "o que é, para você, ensinar literatura"? E o ensino de literatura vai muito além dessas mudanças.

Na resposta do Aluno 5, ainda encontro "Para mim, ensinar literatura é ensinar os tipos de textos, ou seja, para cada ocasião existe uma maneira de se escrever e esse expressar". Trabalhar diversos gêneros ou tipos textuais é objetivo do ensino de Língua Portuguesa, como os próprios Parâmetros Curriculares Nacionais (1997) apontam, e destaco que os 
textos literários, mais do que gêneros textuais dentre tantos outros, fazem parte de um campo do saber específico, com objetivos distintos da área Língua Portuguesa. A Literatura é, sim, feita através de palavras, assim como a Filosofia, a Sociologia, a História, entre tantos outros campos, mas a ela é possível subverter as palavras, questionar as ordens das mesmas, a moral humana, repensar a ética; é um campo que, de acordo com Sartre, abarca todos os Outros.

Apenas o Aluno 1 pensa o ensino de forma que possamos aproximar o que ele disse da ideia de meta-aprendizado que postulamos ao longo deste trabalho. Ele vislumbra a possibilidade de o ensino literário auxiliar o aluno a, de alguma forma, agenciar o seu próprio aprendizado, buscar conhecimento sobre "a cultura, o passado, o presente e muitas vezes sobre si mesmo". As demais respostas, como vimos, não podem ser associadas a uma visão em que a literatura auxiliaria as pessoas no desenvolvimento metacognitivo. O que se pode ser é que quando não relacionada a um conteúdo de ensino, a literatura é tida como um escape, uma via de fuga da realidade.

A partir das respostas obtidas no questionário, devo concordar com Michéle Petit (2009), quando diz que, no Brasil, assim como em vários outros países, não é fácil transmitir o 
gosto da leitura aos adolescentes, sobretudo se cresceram nos meios populares, os quais veem os livros literários como objetos desprovidos de sentido. A maior parte dos jovens com que Petit se deparou só tinha conhecido a leitura literária na escola, "o que não Ihes trazia boas lembranças: 'a escola foi uma experiência sem valor', comenta Val, 'a leitura era obrigatória, imposta, aprendi apenas a memorizar os textos, o ato de ler não tinha nenhum sentido, eu só decifrava símbolos'” (PETIT, p.39). Faço um paralelo com meus alunos que viam a literatura como escape do real, como forma de aprender tipos de textos ou regras gramaticais, uma vez que, acredito que a escola deles também não os estimulou a tornarem-se leitores.

A visão acerca da literatura e de seu ensino, que pode ser depreendida das respostas analisadas acima, acaba por reforçar alguns aspectos que discutimos anteriormente, com destaque para a falta de objetivos de leituras nas aulas de literatura, bem como o desconsiderar o conhecimento do aluno no processo de ensino-aprendizagem. A maior parte das respostas se mostrou insatisfatória e demonstrou que muitos sempre veem a literatura como meio de aprender outra coisa (Língua Portuguesa: gramática, escrita, leitura; história, por exemplo). Possivelmente, enquanto alunos do 
ensino básico, os estudantes de Pedagogia que responderam às questões que passei não foram estimulados a desenvolver atividades de meta-aprendizado.

Para implementar um ensino de literatura de qualidade e formar leitores, é imprescindível que se ajudem e se instiguem as pessoas a gerenciarem suas propriedades de pensar e os objetivos de suas ações. A sala de aula é espaço privilegiado nesse processo, local em que se pode estimular os alunos a desenvolverem técnicas que lhes ajudarão no meta-aprendizado e no conhecimento de si mesmos (GERHARDT et al, 2015). Ali notamos as falhas do ensino; por isso, somente ao pensarmos a partir daquele espaço é que poderemos traçar novas estratégias, inclusive, de formação de profissionais qualificados.

\section{CONSIDERAÇÕES FINAIS}

Enquanto educador e pesquisador acredito que 0 conceito de meta-aprendizado converge diretamente com a habilidade necessária para a leitura do texto literário, uma vez que, a partir dele, é possível refletir e propor um ensino de literatura em que se respeitem e considerem os conhecimentos/desejos dos alunos, e se contribua para que eles se tornem sujeitos ativos na construção de seu próprio conhecimento, reconhecendo-os enquanto pessoas 
distintas que possuem maneiras diferentes de aprender. A partir do momento em que esses mesmos alunos tornaremse mais conscientes acerca da maneira como aprendem, dos processos (ações e comportamentos) necessários para que controlem o seu próprio aprendizado, terão mais autonomia para aprender e possivelmente maior sucesso no processo de ensino-aprendizagem/leitura de textos literários.

Ademais, ao refletir no por que e para quê ensinar literatura nas escolas, penso que é preciso entender, com Antonio Candido (1995, p.174-175), que “[...] a literatura aparece claramente como manifestação universal de todos os homens em todos os tempos. [...] Ela se manifesta desde o devaneio amoroso ou econômico do ônibus até a atenção fixada na novela de televisão ou na leitura seguida de um romance". Ou seja, a literatura está presente na vida humana desde que temos consciência acerca da nossa existência. No tocante à educação, desde muito pequeninas, antes de começarem a falar, muitas crianças já têm contatos com histórias fantásticas, seja através da leitura empreendida por algum familiar, seja assistindo televisão e desenhos infantis. Isso é muito interessante, pois, quando a escola se propõe a ensinar apenas aquilo que os estudantes "teoricamente" não sabem, acaba por perder os conhecimentos de mundo que trazem consigo dos outros espaços que frequentam. 
Esse pensamento "não identifica os saberes prévios dos alunos como parte da construção do aprendizado e não problematiza o aspecto processual e, por isso, a cada vez sempre único, da relação entre texto e leitor" (GERHARDT et al, 2015, p.187). Com certeza, isso contribui e muito para o fracasso escolar dos alunos nas aulas de literatura e nos conhecimentos de leitura de um modo mais amplo.

É claro que a Universidade e os cursos de licenciatura, de um modo geral, devem se preocupar, conforme Ana Lúcia Guedes-Pinto (2015, p.20), com a formação de profissionais qualificados para atuar junto ao grupo social de seus alunos, planejando e organizando situações e vivências que propiciem o processo de apropriação do conhecimento sistematizado e acumulado pelo grupo cultural ao qual pertencem. Para tanto, eles devem ser capazes de atualizar o seu próprio conhecimento e de se tornar cada vez mais autônomos, "capaz de, mediante a transformação do seu procedimento didático, sentir-se transformando também a sua ação política" (ANDRADE, 2004, p.100). No caso do ensino de literatura, é preciso que os pedagogos e professores da área de Língua Portuguesa compreendam antes mais nada o motivo de ensinar, aprender e ler obras literárias, e que entendam que ensinar é muito além de ditar regras a serem decoradas e receber alunos que não 
possuem conhecimentos prévios; ensinar é uma atividade de constante diálogo em que tanto professor quanto aluno serão aprendizes. No caso dos docentes e da formação deles, é necessário que estimulem os alunos para que possam tornar-se cada vez mais autônomos no agenciamento de seu próprio aprendizado. Uma das formas de fazer isso é trazer a leitura para as aulas enquanto prática significativa. Ou seja, é necessário cada vez mais se pensar no ensino enquanto uma construção de saberes sobre a prática literária por parte das pessoas.

\section{REFERÊNCIAS}

ABREU, Marcia (2006). Cultura letrada: literatura e leitura. São Paulo: Editora UNESP.

BRASIL (1997). Parâmetros Curriculares Nacionais - Língua Portuguesa (5a à 8 a séries). Secretaria da Educação Fundamental. Brasília: Ministério da Educação.

CADERMATORI, Lígia (1986). O que é literatura infantil. São Paulo: Brasiliense.

CANDIDO, Antonio (1995). "O direito à literatura”. In: Vários Escritos. São Paulo: Duas cidades.

CALVINO, Ítalo (2007). Por que ler os clássicos. Trad. Nilson Moulin. São Paulo: Cia das Letras.

GERHARDT, Ana Flávia Lopes Magela; BOTELHO, Patrícia Ferreira; AMANTES, Aline Mendes (2015). Metacognição, objetivos de leitura e atividades didáticas de língua portuguesa. Revista Brasileira de Linguística Aplicada, Belo Horizonte, 15(1), p.180-208. In http://www.scielo.br/scielo. php?pid=S1984-63982015000100180\&script=sci_abstract \&tlng=pt Acesso em 20.Jul.2017. 
GUEDES-PINTO, Ana Lúcia (2015). Práticas de escrita na formação de professores: indícios de apropriação da profissão docente. Campinas: Mercado das Letras.

JACKSON, Norman (2004). Developing the concept of metalearning. Innovations in Education and Teaching International, 41(4), p.391-403.

MACHADO, Rodrigo Corrêa Martins (2017). "Leitura literária na escola: algumas reflexões sobre o ensino de literatura na educação básica brasileira". In: AMORIM, Marcel Álvaro de (ORG.). Ensino de Literaturas: perspectivas em Linguística Aplicada. Campinas: Pontes Editores, p.51-70. MEIRELES, Cecília (1977). “O mosquito escreve”. In: Ou isto ou aquilo. Rio de Janeiro: Civilização Brasileira - INL, p.40.

PETIT, Michele (2009). A arte de ler - ou como resistir à adversidade. São Paulo: Ed. 34.

SARTRE, Jean-Paul (2013). O existencialismo é um humanismo. João Batista Kreuch (Trad.). Petrópolis: Vozes.

TODOROV, Tzevetan (2010). A literatura em perigo. Caio Meira (Trad). Rio de Janeiro: Difel.

WALTY, Ivete Lara Camargos (2011). "Literatura e escola: antilições". In: EVAGELISTA, Aracy Alves Martins; BRANDÃO, Heliana Maria Brina; MACHADO, Maria Zélia Versiani. Escolarização da leitura literária. 2.ed. Belo Horizonte: Autêntica, p.49-58.

Rodrigo Corrêa Martins Machado é Doutor em Literatura Comparada pela Universidade Federal Fluminense, professor Adjunto da área de Didática de Língua Portuguesa e Literaturas do Instituto de Educação de Angra dos Reis da Universidade Federal Fluminense. 